\title{
Clinical Study of Pulmonary Hydatid Diseases in a Government Tertiary Hospital
}

\author{
Dr.Rajendra Prasad Potlabathini ${ }^{1}$, Dr.Arun Kanala ${ }^{2}$, Dr.Shankar Reddy Dudala ${ }^{3}$ \\ ${ }^{I}$ Dr.Rajendra Prasad Potlabathini, M.S., M.Ch. CTVS, Associate Professor, Department of C.T.Surgery, \\ Osmania Medical College/ Osmania General Hospital, Afzalgunj, Hyderabad, Telangana State- 500012. \\ ${ }^{2}$ Dr.Arun Kanala, M.S., M.Ch. CTVS, Assistant Professor, Department of C.T.Surgery, Osmania Medical \\ College/ Osmania General Hospital , Afzalgunj, Hyderabad Telangana State - 500012. \\ ${ }^{3}$ Dr.Shankar Reddy Dudala, MD, Assistant Professor, Department of Community Medicine, S.V. Medical \\ College, Tirupati, AP
}

\begin{abstract}
:
Introduction: The hydatid is endemic zoonotic disease where livestock is raised in association with dogs. Aims and objectives: To define the clinical and epidemiological profile for hydatid diseases among the patients reporting to a tertiary teaching hospital.

Material and methods: Retrospective Hospital based study was carried out on a total of $(n=28)$ patients admitted in the Department of Department of C.T.Surgery, Osmania Medical College/ Osmania General Hospital, Hyderabad between 1st June 2010 to $29^{\text {th }}$ Februray 2012. Descriptive statistics (percentage), were used in analyzing the patient characteristics and laboratory parameters.

Conclusion: All cases are Echinococcus granulosus. During the study period 28 cases fulfilled the inclusion and exclusion criteria. Majority of the patients had complaints in chest region, followed by haemoptysis. Majority of the patients (\%) had decreased breath sounds.
\end{abstract}

Keywords: Hydatidosis, Echinococcosis, Epidemiology

\section{Introduction}

Echinococcosis or hydatidosis, caused by the larval stage of Echinococcus granulosus (E. granulosus), is an important public health problem in many areas of the world, particularly among populations that practice sheep husbandry [1]. Due to its varied morphological presentations and involvement of various sites in the body it gives rise to varying clinical symptomatology. Hydatid cysts may grow faster in the lung than in the liver, due to less the elasticity of the lungs parenchyma [2]. Echinococcosis is usually found in the liver (with prevalence of 50-70\%) and lung (20-30\%) [3], although hydatid cysts can occur in any location including in the peritoneal cavity, retroperitoneum, spleen, kidney, adrenal glands, brain, spine, myocardium and abdominal wall [4]. There is a general agreement about the central role of surgery in the management of pulmonary hydatidosis and the adjuvant value of medical therapy.

Pleural manifestation may develop as a complication of pulmonary hydatid disease, which does not involve a parasitic infestation. The rupture of a hydatid cyst in the pleura can cause a wide range of clinical and radiographic symptoms, such as pneumothorax, hydropneumothorax, empyema, abscess formation, pleural thickening, and tension pneumothorax, to develop in the pleural area. The diagnosis is sometimes very difficult and even confused with malignancies. Perforated hydatid cysts emerge as a distinct entity that should especially be considered in differential diagnoses. Opening of the hydatid cyst to the pleura can be spontaneous and can also develop as a result of trauma or iatrogenically.

\section{Materials and Methods}

Retrospective Hospital based study was carried out on a total of $(\mathrm{n}=28)$ patients admitted in Department of C.T.Surgery, Osmania Medical College/ Osmania General Hospital Hyderabad from $1^{\text {st }}$ June 2010 to $29^{\text {th }}$ Februray 2012. Informed written consent was taken from all the study subjects. Because the cases were consulted on for complicated clinical and radiological symptoms, a wide range of diagnostic methods were utilized for the diagnosis. A clinical and radiological evaluation was performed initially. Routine plain and lateral chest radiography, computed thorax tomography (CT), abdominal tomography and abdominal ultrasonography, and, in some cases, magnetic resonance imaging (MRI) were used. Routine hematological and biochemical analyses were performed on the cases. Immunological tests like casoni's intradermal test, Weinberg complement fixation test, ARC 5 Test are used in diagnosis.

In the evaluation of the perforated cyst, the cyst was considered to be a complicated cyst regardless of whether it was infected. Pleural abnormalities were categorized as pleural thickening, free fluid, pneumothorax, 
and hydropneumothorax radiographically. In those cases with pleural fluid, biochemical and microbiological evaluations were performed. In cases in which the pleural fluid was purulent, the empyema evaluation was assessed by considering the findings of the microbiological examinations.

Inclusion criteria: Patients diagnosed with pulmonary Hydatid diseases.

Exclusion criteria: Case sheets which were incomplete and which had missing data due to the non availability of patients.

\section{Results}

Table 1: Clinical findings of Pulmonary Hydatid diseases (Chief complaints, Localised signs, Chest X-ray findings, Spectrum of pulmonary Hydatid disease, Lobe involvement of disease and surgical approach)

\begin{tabular}{|c|c|}
\hline Chief complaints & Frequency $(\%) *$ \\
\hline Cough & $12(42.9)$ \\
\hline Dyspnea & $8(28.6)$ \\
\hline Chest pain & $11(39.3)$ \\
\hline Asymptomatic & $2(7.1)$ \\
\hline Expectoration of grape skins & $1(3.6)$ \\
\hline Fever & $8(28.6)$ \\
\hline Haemoptysis & $10(35.7)$ \\
\hline Loss of weight & $3(10.7)$ \\
\hline Localised signs & Frequency $(\%)$ \\
\hline Decreased chest movements & $6(21.4)$ \\
\hline Dull note on percussion & $5(17.9)$ \\
\hline Decreased breath sounds & $17(60.7)$ \\
\hline Chest X-ray findings & Frequency $(\%)$ \\
\hline Rounded or oval opacity (Escudero nenerow sign) & $23(82.1)$ \\
\hline Water lily appearance (Camalote sign) & $4(14.3)$ \\
\hline Homogenous opacity & $1(3.6)$ \\
\hline Spectrum of pulmonary Hydatid disease & Frequency (\%) \\
\hline Type I & $22(78.6)$ \\
\hline Type II & $4(14.3)$ \\
\hline Type III & 0 \\
\hline Type IV & $2(7.1)$ \\
\hline Lobe involvement of disease & Frequency $(\%)$ \\
\hline Right upper lobe & $10(35.7)$ \\
\hline Left upper lobe & $3(10.7)$ \\
\hline Right middle lobe & $3(10.7)$ \\
\hline Lingual & $1(3.6)$ \\
\hline Right lower lobe & $3(10.7)$ \\
\hline Left lower lobe & $8(28.6)$ \\
\hline Type of Surgical approach & Frequency $(\%)^{* * *}$ \\
\hline Right posterior lateral thoracotomy & $16(57.1)$ \\
\hline Left posterior lateral thoracotomy & $11(39.3)$ \\
\hline
\end{tabular}

Note: *More than one complaint

** One case was managed conservatively

During the study period 28 cases fulfilled the inclusion and exclusion criteria. Majority of the patients had complaints in chest region, followed by haemoptysis. Majority of the patients (\%) had decreased breath sounds. Majority of the patients had been diagnosed based on Rounded or oval opacity (Escudero nenerow sign) $(82.1 \%)$ in Chest X-rays, followed by Water lily appearance (Camalote sign). Majority of the patients (78.6\%) were having type I spectrum of pulmonary Hydatid disease. Right upper lobe (35.7\%) was involved in majority of the patients followed by Left lower lobe. Chest X -ray was the sheet anchor in the diagnosis of pulmonary hydatid disease. Blood picture elevation of total leukocyte count with a range from 6,300-114,500/cu mm. Differential leukocyte count showed evidence of eosinophilia ranging from $8-13 \%$. Erythrocyte sedimentation rate estimated at the end of one hour elevated in all cases ranging from $10-38 \mathrm{~mm}$. Two patients had prolonged air leak for more than 10 days requiring prolonged intercostal drainage.

Table 2: Epidemiological Characteristics of Pulmonary Hydatid diseases (Age, gender and locality distribution of pulmonary Hydatid diseases)

\begin{tabular}{|l|l|l|l|}
\hline \multirow{2}{*}{ Age group in years } & \multicolumn{2}{|l|}{ Frequency (\%) } & \multirow{2}{*}{ Total (\%) } \\
\cline { 2 - 3 } & Male & Female & \\
\hline$\leq 15$ & 1 & 0 & $1(3.6)$ \\
\hline $15-30$ & 4 & 6 & $10(35.7)$ \\
\hline $30-45$ & 6 & 8 & $14(50)$ \\
\hline $45-60$ & 1 & 1 & $2(7.1)$ \\
\hline$\geq 60$ & 0 & 1 & $1(3.6)$ \\
\hline Total & $\mathbf{1 2 ( 4 2 . 9 )}$ & $\mathbf{1 6}(\mathbf{5 7 . 1})$ & $\mathbf{2 8 ( 1 0 0 )}$ \\
\hline
\end{tabular}




\begin{tabular}{|l|l|l|l|}
\hline Locality & Male & Female & Total (\%) \\
\hline Rural & 8 & 14 & $22(78.6)$ \\
\hline Urban & 4 & 2 & $6(21.4)$ \\
\hline Total & $\mathbf{1 2 ( 4 2 . 9 )}$ & $\mathbf{1 6}(\mathbf{5 7 . 1})$ & $\mathbf{2 8}(\mathbf{1 0 0})$ \\
\hline
\end{tabular}

The average age was 30 years with a range from $4-65$ years. Majority (50\%) of the patients were from $30-45$ year age group, followed by $15-30$ year age group (35.7\%). Majority $(57.1 \%)$ of the patients were female when compared to male (42.9\%). Majority $(78.6 \%)$ of the patients were from rural background when compared to urban $(21.4 \%)$ areas.

\section{Discussion}

Most human infections are due to E. granulosus transmitted between domestic dogs and livestock while the other species with significant zoonotic potential is E. multilocularis that occurs naturally in fox definitive hosts and small mammal intermediate hosts [5]. These two species cause human cystic or alveolar echinococcosis respectively, which may be considered serious public health problems in several regions including developed countries in the endemic area [6].

Pulmonary hydatid cysts and their complications have been known to exist since the time of Hippocrates [7]. Majority of the patients had complaints in chest region, followed by haemoptysis. Other studies reported that common presentation in the study was pain abdomen [6], this might be due to inclusion of all organs effected by hydatid infections.

Qian devised a clinical classification scheme for thoracic hydatid disease [8]. In the present study, majority of the patients were suffering from cough, chest pain, haempotysis, dyspnoea, etc when compared with a study by Sayir et al where due to pleural rupture, the most frequent symptom was dyspnea in patients (44 cases, $57.8 \%$ ). Other symptoms included cough (42 cases, 55.2\%), chest pain (39 cases, 51.3\%), fatigue (32 cases, $42.1 \%$ ), and fever (28 cases, $36.8 \%){ }^{9}$ As a result of the pulmonary hydatid cyst perforating the pleura, symptoms such as chest pain, coughing, cyanosis, fever, and shortness of breath develop. As a result of the rupture of the cyst, the cyst contents pour into the pleura, and the ruptured germinative membrane collapses. Therefore, signs of compression occur in the latent lung parenchyma [9].

A hydatid cyst is diagnosed with radiology (X-ray, computed tomography, MRI, ultrasound), serological investigations, and pathological examinations [10]. Thoracic hydatid cysts are diagnosed on the basis of radiological findings $[11,12]$. Surgical treatment remains the most valid method of treatment for a pulmonary hydatid cyst, regardless of whether it is symptomatic [13]. Treatment was in the form of surgery for all our cases.

The youngest patient with pulmonary hydatid disease in the present study was 4 years when compared to one year old reported by Kavukcu et al. [14], and two and a half years old by Nazar et al. [15], Fifty seven percent of our patients were females. Similar findings were seen in Nazar et al.[15], Al-Mukhtar, from Iraq [16] and Yaghan et al. from Jordan [17]. In contrast, some authors reported slightly higher prevalence among males [14]. "Women in rural areas are closely associated with domestic and farm duties, such as milking animals and cultivating crops while most men are military or government personnel" [16].

The disease can progress asymptomatically for a long time and can occur alongside various other diseases, such as pneumonia, empyema, pneumothorax, pyopneumothorax or tension pneumothorax. Invasive procedures, such as thoracentesis or the use of anthelmintic drugs, can lead to complicated hydatid disease, and trauma can also be a cause of the pleural perforation of the cyst. Pleural perforation can sometimes lead to lifethreatening emergency situations, such as tension pneumothorax. The delayed referral of patients to physicians causes the disease to become more complicated and leads to an increase in morbidity and mortality. The treatment of the disease is in the form of surgery. Possible parenchymal protection should be applied during the surgical treatment, and anatomic resection should not be performed unless necessary [14].

\section{Conclusion}

All cases are Echinococcus granulosus. Surgery is the main modality of treatment. Intact endo cystectomy without aspiration is the method of choice in our Institution. Still Chest X-ray and CT Scan Chest is the main basic investigation by which most of the pulmonary hydatid cysts are diagnosed. Possible parenchymal protection should be applied during the surgical treatment, and anatomic resection should not be performed unless necessary.

\section{Acknowledgement}

The authors are grateful to authors/editors/publishers of all those articles, journals and books from where the literature for this article has been reviewed and discussed. 


\section{References}

[1] Heidari Z1, Mohebali M, Zarei Z, Aryayipour M, Eshraghian M, Kia E, et al. Seroepidemiological study of human hydatidosis in meshkinshahr district, ardabil province, iran. Iran J Parasitol. 2011 Aug;6(3):19-25.

[2] Montazeri, V, Sokouti M, Rashidi H. Comparison of pulmonary hydatid disease between children and adult. Tanaffos. 2007;6(1):13-18.

[3] Simindokht S, Mohammad R, Mehrdad H, Hooman Y. Epidemiological, clinical and paraclinical study of hydatid cysts in three educational medical centers in 10 years. The Journal of Shaheed Sadoughi University of Medical Sciences. 1990;8(1):25-9.

[4] Eckert J, Deplazes P. Biological, epidemiological, and clinical aspects of echinococcosis, a zoonosis of increasing concern. Clin Microbiol Rev. 2004 Jan;17(1):107-35..

[5] Craig PS, Rogan MT, Campos-Ponce M. Echinococcosis: disease, detection and transmission. Parasitology. 2003;127 Suppl:S5-20.

[6] Jawed A, Najnin K, Siddarth R. Clinico epidemiological profile of hydatid diseases in central india, a retrospective and prospective study. Int J Biol Med Res. 2011; 2(3): 603-606.

[7] Symbas PN, Aletras H. Hydatid disease of the lung. In: Shields TW, editor. General Thoracic Surgery. 5th ed. Philadelphia: Lippincott Williams\&Wilkins; 2000. pp. 1113-22.

[8] Qian Z: Thoracic hydatid cysts. A report of 842 cases treated over a thirty year period. Annals of Thoracic surgery. 1988;46:342.

[9] Sayir F, Cobanoglu U, Sehitogullari A. Surgical treatment of pulmonary hydatid cysts, which perforated to the pleura. Eurasian J Med. 2012 Aug;44(2):79-83. doi: 10.5152/eajm.2012.19.

[10] Lightowlers MW, Gottstein B. Echinococcosis/hydatidosis: Antigens, immunological and molecular diagnosis. In: Thompson RCA, Lymbery AJ, editors. Echinococcus and hydatid disease. Wallingford, UK: CAB international; 1995. pp. 355-410.

[11] al Karawi MA, Mohamed AR, el Tayeb BO, Yasawy MI. Unintentional percutaneous aspiration of a pleural hydatid cyst. Thorax. 1991 Nov;46(11):859-60. [PMC free article] [PubMed]

[12] Won Sinner WN. New diagnostic signs in hydatid disease: radiography, ultrasound, CT and MRI correlated to pathology. Eur J Radiol. 1991;12:150-9. [PubMed]

[13] Guidelines for treatment of cystic and alveolar echinococcosis in humans. WHO Informal Working Group on Echinococcosis. Bull World Health Organ. 1996;74:231-42. [PMC free article] [PubMed]

[14] Kavukcu, S., Kilic, D., Tokat, A.O., Kutlay, H., Cangir, A.K., Enon, S., et al. Parenchyma-preserving surgery in the management of pulmonary hydatid cysts. J Invest Surg. 2006 Jan-Feb;19(1):61-8.

[15] Nazar B. Elhassani, Abdulsalam Y. T. Management of pulmonary hydatid disease: Review of 66 Cases from Iraq. Case Reports in Clinical Medicine. 2015;4,77-84.

[16] Al-Mukhtar, A.S. Prevalence of Hydatid Cysts in Slaughtered Animals in Basra (South of Iraq). Emirates Medical Journal.1989;17:87.

[17] Yaghan RJ1, Bani-Hani KE, Heis HA. The clinical and epidemiological features of hydatid disease in Northern Jordan. Saudi Med J. 2004 Jul;25(7):886-9. 